\title{
ADAPTACIÓN DA DOCENCIA DE FISIOLOXÍA HUMANA ANTE A PANDEMIA DA COVID-19
}

\author{
de Labra Pinedo, Carmen ${ }^{1}$; Sangiao Alvarellos, Susana² \\ ${ }^{1}$ Universidade da Coruña, Departamento de Fisioterapia, Medicina e Ciencias Biomédicas, \\ Facultade de Enfermaría e Podoloxía \\ https://orcid.org/0000-0002-5306-0475 \\ ${ }^{2}$ Universidade da Coruña, Departamento de Fisioterapia, Medicina e Ciencias Biomédicas, \\ Facultade de Enfermaría e Podoloxía, \\ https://orcid.org/0000-0003-1207-4667
}

\section{RESUMO}

A pandemia causada polo SARS-CoV-2 provocou un cambio no modelo educativo, principalmente polas medidas de seguridade adoptadas. 0 obxectivo do presente traballo é analizar os resultados da aprendizaxe a distancia na materia de Fisioloxía do grao en Podoloxía e Enfermería, pertencentes á UDC.

PALABRAS CLAVE: Covid-19, Aprendizaxe virtual, Ciencias da Saúde

\section{CITA RECOMENDADA:}

de Labra Pinedo, Carmen; Sangiao Alvarellos, Susana (2021): Adaptación da docencia de Fisioloxía Humana ante a pandemia da Covid-19. En García Naya, J.A. (ed.) (2021). Contextos universitarios transformadores: a nova normalidade académica. Leccións aprendidas e retos de futuro. $V$ Xornadas de Innovación Docente. Cufie. Universidade da Coruña. A Coruña (pág. 135-142).

DOI capítulo: https://doi.org/10.17979/spudc. 9788497498180.135

DOl libro: https://doi.org/10.17979/spudc. 9788497498180 


\section{ABSTRACT}

The pandemic caused by SARS-CoV-2 has caused a change in the educational model, mainly due to the security measures adopted. The objective of this work is to analyze the results of distance learning in the Physiology subject of the degree in Podiatry and Nursing, belonging to the UDC.

KEY WORDS: Covid-19, Virtual Learning, Health Sciences 


\section{INTRODUCCIÓN}

A principios do 2020, a enfermidade por coronavirus 2019 (COVID-19) causada polo virus SARS-CoV-2, con orixe en Wuhan, provincia de Hubei, evolucionou desde China a case todas as partes do planeta (Wang et ao., 2020). En marzo, a Organización Mundial da Saúde (OMS) declarou 0 brote de coronavirus como pandemia. 020 de maio de 2020, a OMS confirmou 4761559 casos da enfermidade por COVID-19 en todo o mundo, 317529 mortes e 216 países, áreas ou territorios afectados.

Os problemas relacionados coa saúde, que aparecen entre 2 e 14 días despois da infección, inclúen febre, tose, fatiga e dificultade para respirar (Guan et al., 2019). Outros síntomas clínicos menos comúns inclúen infección do tracto gastrointestinal, como diarrea ou vómitos, ou alteración do sistema neurolóxico, como dor de cabeza, náuseas ou perda do gusto ou olfacto. Aínda que a maioría dos pacientes recupérase da infección, $030 \%$ require hospitalización e 05 \% require coidados intensivos debido a unha infección aguda do tracto respiratorio e pneumonía. Entre os factores de risco de COVID-19 atópanse a idade, a hipertensión, as enfermidades cardiovasculares, a diabetes e a inmunosupresión (Huang et al. 2020; Chen et al., 2020; Zhou et al., 2020).

A transmisión de pacientes ou portadores de incubación do SARS-CoV-2 ocorre principalmente entre persoas que están en contacto íntimo. Para previr a transmisión e retardar a taxa de infección, a OMS deu varias precaucións simples, entre elas lavarse as mans regularmente con auga e xabón, ou limpalas cun desinfectante para mans a base de alcol; manter polo menos 1 metro de distancia entre as persoas; evitar tocarse a cara; cubrirse a boca e o nariz ao tusir ou esbirrar; quedarse na casa cando se presenten síntomas; e absterse de fumar e outras actividades que debiliten os pulmóns. Estas respostas condutuais non só cambian a nosa rutina diaria, senón que tamén traen consigo inseguridade e perda de liberdade, todo o cal pode ter efectos colaterais nas dimensións psicolóxicas dos individuos. 
Desde marzo do 2020, a pandemia causada polo SARS-CoV-2 provocou unha situación sen precedentes en todo o mundo, xa que, engadido á súa alta capacidade de contaxio, o virus pode provocar enfermidades potencialmente mortais (Woolliscroft, 2020). Para previr 0 contaxio e retardar a taxa de infección, a OMS deu unha serie de pautas a seguir o que fixo que os nosos estudantes tivesen que cambiar a súa forma de aprender e adaptarse de forma urxente a un novo modelo educativo a distancia.

Dentro deste novo contexto pandémico, o ensino en xeral, e a universidade en particular, detiveron a docencia presencial, provocando que 0 estudantado non puidese recibir as súas clases no formato habitual, e todo isto nun intento de gañarlle a batalla ao virus. Con todo, a universidade non parou, senón que se transformou de maneira inmediata a unha educación non presencial, en liña. Esta rápida transformación, levou consigo moitos desafíos, aos que 0 profesorado tivo que adaptarse. 0 obxectivo principal do traballo centrouse en analizar os resultados da aprendizaxe a distancia na materia de Fisioloxía dos grao en Podoloxía e Enfermería, pertencentes á Universidade da Coruña.

\section{Contorna académica}

A experiencia aplícase á materia de Fisioloxía Humana, onde imparten docencia dúas profesoras da área. A transformación consistiu en difundir o material previsto para cada unha das clases semanais a través de diapositivas que incluían contidos específicos, ademais de engadir en off a voz coa explicación da mesma. Como estas sesións podíanse ver en diferido, 0 alumnado podíase beneficiar dun gran número de sesións para resolver dúbidas, realizar exposicións ou levar a cabo algunha discusión guiada dun tema, sempre a través da plataforma Teams, que permite a videoconferencia, e por tanto pódense ter en conta as expresións faciais e a linguaxe corporal, o que fomenta a interacción social en tempos de pandemia.

Coa intención de dar protagonismo ao estudantado, e que fosen eles quenes preparasen con antelación a materia, decidiuse empregar nos grupos de docencia interactiva a aula invertida 
de maneira en liña, sendo esta moi similar á convencional, salvo que no modo en liña as sesións de discusión debían darse en liña. Para iso, previo á sesión de docencia interactiva subíase no campus virtual unha actividade, como podería ser 0 visionado dun vídeo ou a lectura dun artigo de investigación relacionado coa materia. Unha vez traballada a actividade por parte do alumnado, promovíase unha aprendizaxe activa, onde 0 estudantado, a través do seu labor agora si en grupo, puidese resolver os problemas expostos por parte da docente. Nestas sesións de discusión dividiuse ao grupo total de alumnos/as en tres grupos reducidos duns 20 estudantes cada un. Cada un destes tres grupos recibía a sesión de discusión a unha hora diferente. 0 desenvolvemento habitual desta clase de grupos reducidos consistía na presentación por parte do profesorado dunhas preguntas dedutivas, relacionadas co material subido ao campus virtual. Esta actividade tiña o propósito de que 0 estudantado relacionase a materia explicada na sesión de docencia expositiva co material traballado na sesión de docencia interactiva. Ademais, como este tipo de docencia virtual se levaba a cabo a través da plataforma Teams, fixéronse diferentes subgrupos de discusión (duns 5 alumnos/as) para que realizasen unha primeira discusión entre eles (discusión dentro do grupo), logo a través de Teams xuntábanse os grupos para que discutisen entre eles (discusión entre grupos), para finalmente facer todos os grupos unha posta en común co profesorado da materia.

Outra variante incluída na docencia foi a de incluír preguntas individuais obrigatorias a través de probas obxectivas que se realizaron a través do campus virtual, e ó realizarse semanalmente, incita a estudar o contido da materia de maneira continua, ofrecendo a vantaxe ao profesorado de ver a progresión da aprendizaxe na súa materia.

\section{DESCRICIÓN DA EXPERIENCIA}

\section{Material e método}

As variables medidas para 0 estudo foron: 1) asistencia do alumnado, 2) rendemento académico (exame final e actividades da aula) mediante a nota media da materia, seguindo os 
criterios marcados na resolución do 15 de setembro de 2011, da Consellería de Educación e Ordenación Universitaria e 3) titoría de final de curso onde se avaliou a satisfacción do alumnado acerca da calidade docente en formato aberto e tamén a través da pregunta: En xeral, estou satisfeito/a con as clases e o profesorado da materia (escala tipo Likert 1 mínimo - 7 máximo).

A mostra compúxose de 115 alumnos alumnos/as matriculados nos Graos de Podoloxía e Enfermería da Universidade da Coruña no curso académico 2018-2019 e 124 alumnos matriculados no curso 2019-2010. Todo o alumnado permitiu, de forma voluntaria, formar parte desta investigación.

Para a análise estatística empregouse o SPSS V.25 (IBM Corp., Armonk, NY, USA).

\section{RESULTADOS}

Os cambios realizados durante a pandemia resultaron beneficios para o noso alumnado. Deste xeito, a asistencia ás sesións de docencia aumentou dun 85.3 \% durante 0 curso 2018-2019 a un $97.0 \%$ no curso $2019-2020$.

En canto á análise das notas que se obtiveron nos cursos académicos 2018-2019 e 201920202, evidenciouse que a nota media obtida na materia aumentou significativamente ( $p<$ 0.0001 ) pasando 0 alumnado dunha cualificación media de 6,8 a 8,1. Tendo en conta as melloras implantadas para atallar a crise da pandemia, e tal e como era de esperar, no curso 2019-2020 o número de suspensos diminuíu en comparación co 2018-2019, pasando dun 15 $\%$ a un $2,3 \%$, mentres que o número de notables aumentou dun $40,8 \%$ a un $75,5 \%$.

Os resultados obtidos na titoría grupal sobre o grao de satisfacción do alumnado coas clases e 0 profesorado da materia aumentou notablemente ao longo do ano de pandemia. Da análise xeral de comentarios puidemos comprobar que os diferentes recursos implicados, unidos ao compromiso por parte do profesorado e 0 alumnado, foi imprescindible para 0 éxito nas cualificacións finais do primeiro grao de enfermería e podoloxía na materia de Fisioloxía. 


\section{CONCLUSIÓNS}

Con este traballo mostrouse que todas as medidas adoptadas na materia de fisioloxía durante a pandemia do SARS-CoV-2 resultaron positivas, mellorando os coñecementos do estudantado tal e como demostra o seu aumento nas cualificacións obtidas. Así mesmo, tamén observamos como a satisfacción coas clases e 0 profesorado mellorou substancialmente. Unha limitación do estudo podería ser que o aumento na titorización durante o curso académico 2019-2020 puidese, por si soa, axudar a aumentar a motivación e a aprendizaxe dos nosos estudantes, independentemente de que a actividade fose presencial ou a distancia. É por iso que máis estudos deste tipo son necesarios antes de concluír nada definitivo.

En definitiva, este traballo pon de manifesto que, o profesorado da área de Fisioloxía da Universidade da Coruña, está preparado para atender a súa docencia de maneira adecuada mesmo cando o formato da mesma cambiei drasticamente nun tempo limitado.

\section{REFERENCIAS}

Chen N, Zhou M, Dong X, et al. Epidemiological and clinical characteristics of 99 cases of 2019 novel coronavirus pneumonia in Wuhan, China: a descriptive study. Lancet 2020;395(10223):507-513.

Coronavirus disease (COVID-19) pandemic. Ginebra, Organización Mundial de la Salud, 2020 (https://www.who.int/emergencies/diseases/novel-coronavirus-2019, consultado el 3 de marzo).

Guan WJ, Ni ZY, Hu Y, et al. Clinical Characteristics of Coronavirus Disease 2019 in China. N Engl J Med 2020 Feb 28. doi: 10.1056/NEJMoa2002032

Huang C, Wang Y, Li X, et al. Clinical features of patients infected with 2019 novel coronavirus in Wuhan, China. Lancet 2020;395(10223):497-506. 
Infection prevention and control: the evidence for clean hands. Ginebra, Organización Mundial de la Salud, 2020 (https://www.who.int/infection-prevention/publications/hh_evidence/en/, consultado el 12 de febrero).

Woolliscroft, J. 0. (2020). Innovation in Response to the COVID-19 Pandemic Crisis. Academic medicine: journal of the Association of American Medical Colleges, 95, 1140-1142.

Zhou F, Yu T, Du R, et al. Clinical course and risk factors for mortality of adult inpatients with COVID-19 in Wuhan, China: a retrospective cohort study. Lancet 2020 Mar 11. doi: 10.1016/S0140-6736(20)30566-3.

Wang, C., Horby, P.W., Hayden, F.G., Gao, G.F. (2020). A novel coronavirus outbreak of global health concern. Lancet, 395, 470-473. 